Malaysian Journal of Social Sciences and Humanities (MJSSH)

Volume 4, Issue 8, December 2019

e-ISSN : 2504-8562

Journal home page:

www.msocialsciences.com

\title{
Pengaruh Kepimpinan Pengajaran Guru Besar, Kompetensi Profesionalisme Guru dan Kompetensi Peribadi Guru Terhadap Efikasi Pengajaran Guru Sekolah Rendah di Zon Pedalaman Sabah
}

\author{
Serirama Ebbie1, Roslee Bin Talip1, Dayang Norizah Ag Kiflee@Dzulkifli1 \\ 1Fakulti Psikologi dan Pendidikan, Universiti Malaysia Sabah (UMS) \\ Correspondence: Serirama Ebbie (seri180675@yahoo.com)
}

\begin{abstract}
Abstrak
Kajian ini bertujuan untuk menentukan kekuatan pengaruh kepimpinan pengajaran guru besar, kompetensi profesionalisme guru dan kompetensi peribadi guru terhadap efikasi pengajaran guru bagi guru-guru sekolah rendah di zon Pedalaman, Sabah. Kajian ini melibatkan 361 responden yang terdiri daripada guru-guru sekolah rendah di zon Pedalaman, Sabah. Pemboleh ubah kajian telah diuji dengan menggunakan statistik deskriptif dan inferensi yang melibatkan skor min, sisihan piawai dan regresi berganda. Instrumen yang digunakan dalam kajian adalah soal selidik yang diadaptasi daripada Principal Instructional Management Rating Scale (PIMRS), Standard Guru Malaysia (SGM) dan Teacher Efficacy Scale (TES) bagi mengumpul data daripada 361 responden yang telah melengkapkan borang soal selidik, daripada 54 buah sekolah rendah yang melibatkan tujuh daerah di zon Pedalaman, Sabah. Persampelan secara rawak digunakan dalam pemilihan responden dalam kalangan guru manakala persampelan bertujuan digunakan bagi menentukan bilangan sekolah yang mewakili setiap daerah seperti yang telah ditetapkan. Statistik deskriptif dan inferensi telah digunakan bagi menghuraikan dapatan kajian. Dapatan kajian menunjukkan bahawa tahap kepimpinan pengajaran guru besar $(\mathrm{Min}=4.52 ; \mathrm{SP}=0.313)$ pada tahap sangat tinggi, kompetensi profesionalisme guru $(\mathrm{Min}=$ 4.41; $\mathrm{SP}=0.295)$ juga pada tahap sangat tinggi dan kompetensi peribadi guru ( $\mathrm{Min}=4.47 ; \mathrm{SP}=0.366)$ juga berada pada tahap sangat tinggi manakala efikasi pengajaran guru $($ Min $=3.96 ; \mathrm{SP}=0.358)$ berada pada tahap tinggi. Data inferensi dianalisis menggunakan regresi berganda. Analisis regrasi menunjukkan pengaruh kepimpinan pengajaran guru besar menyumbang 65 peratus, kompetensi profesionalisme guru menyumbang 65.9 peratus dan kompetensi peribadi guru menyumbang 66.5 peratus terhadap efikasi pengajaran guru dan merupakan peramal yang signifikan kepada tahap efikasi pengajaran guru.
\end{abstract}

Kata kunci: sekolah rendah, zon pedalaman, kepimpinan pengajaran guru besar, kompetensi profesionalisme, kompetensi peribadi, efikasi pengajaran

\section{The Influence of Headmaster Teaching Leadership, Teacher Profesionalisme and Teacher Personal Compentency for Teaching Efficiacy of Primary School Teacher in Interior Zone Sabah}

\begin{abstract}
The purpose of this study was to determine the influence of headmaster teaching leadership, teacher professionalism and personal teacher competency on the efficacy of teacher teaching for primary
\end{abstract}


school teachers in the Interior zone of Sabah. The study involved 361 respondents consisting of primary school teachers in the Interior zone, Sabah. The study variables were tested using descriptive statistics and inferences involving mean scores, standard deviations and multiple regressions. The instruments used in the study were questionnaires adapted from the Principal Instructional Management Rating Scale (PIMRS), Malaysian Teacher Standard (SGM) and Teacher Efficacy Scale (TES) to collect data from 361 respondents who completed the questionnaire form, out of 54 primary school affecting seven districts in the Interior zone, Sabah. Random sampling was used in the selection of respondents among teachers while the sampling was used to determine the number of schools representing each district as determined. Descriptive statistics and inferences have been used to describe the findings. The findings of the study showed that teachers leadership skills (Min $=4.52$; SP $=0.313)$ were very high, teacher professionalism $(\mathrm{Min}=4.41 ; \mathrm{SP}=0.295)$ was also very high and teachers' personal competency $(\mathrm{Min}=4.47 ; \mathrm{SP}=0.366$ ) was also very high while teacher teaching efficacy $(\mathrm{Min}=3.96 ; \mathrm{SP}=0.358)$ was also high. Inference data were analyzed using multiple regressions. Regression analysis showed that the influence of headmaster teaching leadership contributed 65 percent, teacher professionalism competency contributed 65.9 percent and teacher personal competency contributed 66.5 percent to teacher teaching efficacy and was a significant predictor of teacher teaching efficacy level.

Keywords: primary school, interior zone, headmaster teaching leadership, professionalism competency, personal competency, teaching efficacy

\section{Pengenalan}

Efikasi merupakan tanggapan individu terhadap aras keupayaan diri untuk menghasilkan sesuatu tindakan atau kemahiran. Tahap efikasi pengajaran guru merupakan nadi utama yang akan menentukan hala tuju sesebuah sekolah. Henson (2001), menyatakan efikasi pengajaran merupakan ciri-ciri yang perlu ada pada setiap guru agar dapat membantu pelajar dalam perkembangannya. Kepimpinan pengajaran merupakan satu bentuk kepimpinan yang menekankan kepada keberkesanan pelaksanaan proses pengajaran dan pembelajaran (Ishak, 2003). Perkara utama dalam kepimpinan pengajaran ialah untuk memastikan pelaksanaan pengajaran dan pembelajaran di sekolah. Penekanan dalam pengajaran dan pembelajaran merupakan faktor kepada kejayaan akademik murid-murid. Penekanan kepada core-business ini menjadikan sekolah lebih cemerlang dalam pencapaian akademik murid. Kepimpinan pengajaran guru besar merujuk kepada peranan dan tanggungjawab yang dilaksanakan oleh guru besar, yang terdiri daripada membentuk dan menyebarkan matlamat sekolah, membentuk piawai dan harapan positif, menguruskan kurikulum, menyelia dan menilai pembelajaran, mempromosikan peluang pembelajaran kepada murid dan menggalakkan perkembangan profesional kepada guru-guru (Boe Lahui-Ako, 2001).

\section{Latar Belakang Kajian}

Persepsi masyarakat terhadap konsep guru yang berkesan masih merujuk kepada sekolah yang dapat memberi kesan dan pengaruh dalam mempertingkatkan pencapaian akademik sekolah. Prestasi pencapaian akademik sekolah pula dikaitkan dengan kesan daripada amalan pengajaran guru dalam bilik darjah. Kecemerlangan akademik sekolah seringkali dijadikan sebagai penentu tahap keberkesanan sesebuah sekolah. Terdapat banyak kekangan yang harus dihadapi oleh para guru dalam menunaikan tanggungjawab mereka sebagai pendidik sehingga memberi kesan kepada tahap kemajuan akademik. Antara masalah yang perlu dihadapi oleh guru-guru adalah latar belakang pendidikan keluarga pelajar yang tidak tinggi (Muhiddin, 2008) dan kemiskinan (Unit Perancangan Ekonomi Negeri Sabah, 2008). Guru-guru sekolah rendah di zon Pedalaman, Sabah juga menghadapi kesukaran untuk akses kepada pendidikan kerana kemudahan infrastruktur yang sangat terhad. Dalam kajian yang dijalankan oleh Sinagatullin (2001), sekolah Pedalaman tidak memiliki kemudahan makmal dan bahan bantu mengajar, tiada perpustakaan, muzium dan kemudahan bersukan menyebabkan mereka ketinggalan dan terasing. Pelajar tidak dapat aksess kepada pendidikan disebabkan oleh masalah 
kemudahan infrastruktur. Oleh itu, guru telah dijadikan sebagai sumber rujukan utama bagi para pelajar (Sinagatullin, 2001; Barter, 2008).

Guru-guru menghadapi kekurangan akses dalam pendidikan kerana mereka berada di kawasan terpencil. Penyaluran bantuan pendidikan daripada pihak berwajib juga adalah terhad kerana jarak yang jauh dan kos penghantaran yang tinggi. Keadaan bertambah sukar apabila guru-guru tidak dapat menghadiri latihan dalam perkhidmatan kerana jarang terpilih untuk menyertainya (lazimnya latihan dalam perkhidmatan dijalankan di kawasan bandar). Dalam kajian Midthassel et al., (2002), guru-guru kawasan Pedalaman, jarang menghadiri latihan dalam perkhidmatan walaupun latihan tersebut penting sebagai satu sistem sokongan bagi guru dalam meningkatkan kemahiran mengajar dan menghadapai persekitaran di kawasan Pedalaman yang sangat mencabar. Kekurangan menghadiri latihan dalam kalangan guru zon Pedalaman perlu diberi perhatian serius kerana program latihan profesionalisme berfungsi sebagai platform yang membolehkan para pendidik untuk mendapatkan pengetahuan serta kemahiran mengajar (Fetherston, 2007) dan seterusnya membantu meningkatkan pencapaian akademik pelajar (Guskey, 2000). Program seumpama itu juga dianggap sebagai komponen kritikal bagi semua warga pendidik dalam membentuk guru yang berkelayakan tinggi dan beriltizam (Amin, 2008).

Motivasi kerja guru yang menurun juga sering dijadikan isu. Motivasi kerja semakin menurun berlaku apabila seorang guru berasa tidak bersemangat untuk mengajar sehingga hilang fokus, tiada upaya dan semangat untuk menjalankan tugas kerana menghadapi masalah tertentu (M Nur \& Norasmah, 2009).

\section{Pernyataan Masalah}

Dewasa ini, cabaran dunia pendidikan semakin dirasakan oleh guru-guru. Banyak kritikan telah disuarakan oleh masyarakat mengenai kaedah pengajaran dan aktiviti yang dikendalikan oleh guruguru dalam bilik darjah (Pusat Perkembangan Kurikulum, 2003). Keberkesanan guru dalam menjalankan tanggungjawab sebagai pendidik semakin dipertikaikan. Guru sentiasa diingatkan dan ditekankan mengenai peranan dan tanggungjawab sebagai tenaga pengajar agar melaksanakan peranan dengan lebih berkesan khususnya semasa menjalankan pengajaran dan pembelajaran kerana diyakini penyumbang kepada peningkatan pencapaian akademik di sekolah (Hallinger, 2011). Asas kejayaan sesebuah sekolah banyak bergantung kepada guru besar sebagai pemimpin pengajaran dan kordinasi para guru selaku tenaga pengajar. Kenyataan ini bersesuaian dengan Hallinger (2003), yang mendapati kepimpinan pengajaran mempunyai perkaitan yang signifikan dengan kejayaan sekolah dalam bidang akademik. Guru-guru perlu mempunyai kemahiran-kemahiran bukan sahaja kemahiran mengajar, tetapi juga kemahiran mengurus, memimpin, komunikasi yang berkesan dengan guru lain, mampu menyelesaikan masalah, serta mempunyai etika kerja yang tinggi (Nashuha, 2009).

Kegagalan dalam memahami dan menerapkan kaedah pengajaran yang sesuai dalam konteks masalah di zon Pedalaman, Sabah menjadi cabaran kepada guru kerana faktor ini boleh menjadi punca kepada ketidakupayaan pelajar dalam mengikuti proses pengajaran dan pembelajaran dengan berkesan. Situasi ini memberi kesan terhadap tahap efikasi pengajaran bagi guru. Menurut Eppley (2009), guru-guru di Pedalaman memerlukan pendekatan pengajaran yang berbeza dengan guru di bandar disebabkan ciri kehidupan masyarakat (biasanya untuk penduduk pribumi) adalah unik. Guru-guru juga sering dinilai berdasarkan pengalaman guru tersebut dalam bidang pendidikan. Dapatan kajian Mannullang (2002) dan Tillmon (2002), menyatakan semakin bertambah pengalaman seseorang guru dalam pendidikan, semakin bertambah tinggi pengetahuannya. Situasi ini menjadi satu cabaran bagi para guru novis. Masyarakat setempat sentiasa ada keraguan terhadap guru-guru baharu khususnya keupayaan dalam pengawalan bilik darjah.

Tahap kompetensi guru juga sangat penting untuk dikaji bagi guru-guru di zon Pedalaman, Sabah. Tugas seorang guru bukan sahaja mengajar, tetapi turut meliputi tugas lain seperti mengelola aktiviti pelajar, mengurus organisasi, mengurus jawatan kuasa dan bekerjasama dengan guru lain dalam melaksanakan agenda-agenda pendidikan di sekolah. Menurut Nasuha (2009), kesemua elemen seperti kemahiran mengajar, kemahiran mengurus, komunikasi yang berkesan dan mampu menyelesaikan masalah merupakan elemen yang menjurus kepada pembentukan kendiri seseorang guru. Kesepaduan 
antara elemen-elemen kemahiran akan dapat melahirkan insan guru yang bijak berkomunikasi, bijak menyesuaikan diri dengan persekitaran serta berupaya menterjemahkan ilmu pendidikan sebagai satu sumbangan yang bermakna terhadap sekolah khususnya dan dunia pendidikan amnya (Rozanis, 2006). Isu lain yang sering ditimbulkan dalam profesion keguruan adalah berkenaan dengan tahap efikasi pengajaran bagi guru yang semakin menurun. Efikasi pengajaran semakin menurun apabila seorang guru berasa tidak lagi bersemangat untuk mengajar sehingga hilang fokus, tiada upaya dan semangat untuk menjalankan tugas kerana menghadapi masalah tertentu (M Nur \& Norasmah, 2009). Proses pengajaran guru merupakan indeks yang terbaik dalam meningkatkan tahap efikasi pengajaran bagi guru. Penglibatan guru mempunyai implikasi yang kuat bukan sahaja untuk pertumbuhan profesional dan kualiti pengajaran tetapi juga untuk prestasi pelajar-pelajar.

\section{Objektif Kajian}

Berdasarkan kepada pernyataan masalah kajian, penyelidik menetapkan tujuh objektif kajian iaitu:

i. Mengenal pasti tahap skor min kepimpinan pengajaran guru besar, kompetensi profesionalisme guru, kompetensi peribadi guru dan efikasi pengajaran guru dalam kalangan guru-guru sekolah rendah di zon Pedalaman, Sabah.

ii. Mengenal pasti pengaruh kepimpinan pengajaran guru besar, kompetensi profesionalisme dan kompetensi peribadi guru terhadap efikasi pengajaran guru bagi guru-guru sekolah rendah di zon Pedalaman, Sabah.

\section{Soalan Kajian}

Berdasarkan latar belakang kajian dan pernyataan masalah yang telah dikemukakan, beberapa persoalan kajian telah dibentuk:

i. Apakah tahap skor min kepimpinan pengajaran guru besar, kompetensi profesionalisme guru, kompetensi peribadi guru dan efikasi pengajaran guru dalam kalangan guru-guru sekolah rendah di zon Pedalaman, Sabah?

ii. Adakah terdapat pengaruh kepimpinan pengajaran guru besar, kompetensi profesionalisme guru dan kompetensi peribadi guru terhadap efikasi pengajaran guru bagi guru-guru sekolah rendah di zon Pedalaman, Sabah?

\section{Hipotesis Kajian}

Bersesuaian dengan tujuan kajian, hipotesis berikut telah dibentuk untuk meneliti pengaruh kepimpinan pengajaran guru besar, kompetensi profesionalisme guru dan kompetensi peribadi guru terhadap efikasi pengajaran guru bagi guru-guru sekolah rendah di zon Pedalaman, Sabah.

$\mathrm{H}_{\mathrm{o}} 1$ Tidak terdapat pengaruh yang signifikan kepimpinan pengajaran guru besar, kompetensi profesionalisme guru dan kompetensi peribadi guru terhadap efikasi pengajaran guru dalam kalangan guru-guru sekolah rendah di zon Pedalaman, Sabah.

\section{Sorotan Kajian Lepas}

Matlamat umum kepimpinan pengajaran guru besar adalah untuk memperbaiki atau mengekalkan keadaan-keadaan yang menggalakkan pembelajaran pelajar-pelajar. Kemahiran dan kecekapan guru besar mengamalkan kepimpinan pengajaran dalam pengajaran dan pembelajaran adalah wajar (Rahmad \& Shahrir, 2005). Kajian oleh Mohd. Yusri Ibrahim dan Aziz Amin (2014), berjaya mengenal pasti dua elemen yang saling berkait untuk meningkatkan keberkesanan organisasi sekolah iaitu kepimpinan pengajaran guru besar dan kompetensi pengajaran guru. Byrk et al., (2010), mendapati kepimpinan pengajaran mampu memainkan peranan sebagai pemacu perubahan di sesebuah sekolah. Sehubungan 
dengan itu, guru yang berefikasi pengajaran tinggi akan mampu memberi sumbangan terhadap kejayaan sekolah dalam memberi nilai tambah kepada outcome pelajar.

Yusuf Ahmad (2008), menyatakan guru-guru telah melalui pelbagai latihan yang berbeza. Guru-guru juga sentiasa berhadapan dengan masalah apabila bertugas di sekolah. Dalam kajian Yusuf Ahmad (2008), didapati guru kerap menghadapi kejutan realiti, penyesuaian diri kepada persekitaran sekolah dan masalah-masalah berkaitan dengan pengajaran dan pembelajaran. Perkara ini banyak menjejaskan peranan guru sebagai seorang profesional sekaligus mempengaruhi tahap profesionalisme guru berkenaan. Dembo dan Gibson (1985), menyatakan untuk memahami efikasi pengajaran guru dengan lebih mendalam, beberapa kajian perlu dilakukan dengan mengambilkira beberapa faktor seperti pendidikan, sosialisasi guru dan organisasi sekolah. Manakala bagi Ashton dan Webb (1986), efikasi pengajaran guru boleh dibentuk kerana mereka memerlukan keterampilan untuk menjadikan pengajaran lebih berkesan. Gideonse (1982), menyarankan jika efikasi pengajaran diperlukan, latihan guru harus dijalankan dalam masa yang panjang dan melibatkan banyak tempat kerana keadaan sekolah yang tidak sama.

Selaras dengan takrifan efikasi pengajaran itu sendiri yang bermaksud kebolehpercayaan terhadap kemampuannya dalam membantu orang lain, jelas bahawa tahap efikasi pengajaran guru merupakan faktor utama dalam menentukan tahap pencapaian sesebuah sekolah. Ini selaras dengan kajian Tajul Ariffin Nordin dan Nor' Aini Dan (2002), yang menyatakan bahawa konsep ibadah dalam profesion perguruan semakin pudar. Senario ini menyebabkan ramai dalam kalangan pendidik semakin alpa dengan tanggungjawab sebenar mereka sebagai guru. Menurut Liaw (2009), pengaruh pengajaran guru secara kelas dan berkumpulan memainkan peranan penting dalam meningkat efikasi pengajaran guru. Efikasi pengajaran guru boleh meningkat melalui pengalaman yang dilalui dalam pengajaran di kelas dan perbincangan kumpulan.

\section{Metod Kajian}

Kajian ini melibatkan 361 responden daripada 54 buah sekolah sebagai sampel bagi mewakili populasi guru-guru sekolah rendah seramai 5586 di tujuh buah daerah di zon Pedalaman, Sabah. Persampelan secara rawak digunakan dalam pemilihan responden dalam kalangan guru manakala persampelan bertujuan digunakan bagi menentukan bilangan sekolah yang mewakili setiap daerah seperti yang telah ditetapkan. Jumlah sampel kajian ditentukan dengan menggunakan Jadual Penentuan Saiz untuk penyelidikan pendidikan yang dibuat oleh Krejcie dan Morgan (1970) dan Bartlett et al., (2001). Pemboleh ubah kajian telah diuji dengan menggunakan statistik deskriptif dan inferensi yang melibatkan skor min, sisihan piawai dan korelasi Pearson. Kajian ini menggunakan pendekatan kuantitatif dan kaedah yang digunakan ialah kaedah tinjauan. Manakala teknik penggumpulan data dalam kajian ini ialah dengan menggunakan instrumen soal selidik. Soal selidik diadaptasi daripada Principal Instructional Management Rating Scale (PIMRS), Standard Guru Malaysia (SGM) dan Teacher Efficacy Scale (TES). Borang soal selidik diedarkan kepada responden yang dipilih secara rawak daripada beberapa buah sekolah, bertujuan untuk mengenal pasti pengaruh kepimpinan pengajaran guru besar, kompetensi profesionalisme guru dan kompetensi peribadi guru terhadap efikasi pengajaran guru. Penggunaan borang soal selidik adalah sesuai kerana kaedah ini mengurangkan masa dan kos kajian (Gay dan Peter, 2003). Penggunaan borang soal selidik juga dapat mengelakkan responden daripada dipengaruhi oleh penyelidik (Sabitha Marican, 2009). Item yang seragam memudahkan penyelidik untuk menganalisis data (Ahmad Mahzan Ayob, 1995

\section{Dapatan Kajian dan Perbincangan}

\section{Analisis Skor Min}

Jadual 1 menunjukkan min keseluruhan bagi pemboleh ubah kepimpinan pengajaran guru besar ialah $4.52(\mathrm{SP}=.34)$. Nilai min ini menunjukkan bahawa pemboleh ubah kepimpinan pengajaran guru besar mempunyai nilai kepimpinan pengajaran pada tahap yang sangat tinggi. 
Jadual 1: Skor Min Pemboleh Ubah Kepimpinan Pengajaran Guru Besar

\begin{tabular}{llll}
\hline Pemboleh Ubah & Min & Sisihan Piawai & Interprestasi \\
\hline $\begin{array}{l}\text { Kepimpinan Pengajaran } \\
\text { Guru Besar }\end{array}$ & 4.52 & .34 & Sangat Tinggi \\
\hline
\end{tabular}

Guru besar sebagai pemimpin mempunyai motivasi yang tinggi dalam membantu meningkatkan pencapaian akademik dan ko-kurikulum sekolah. Guru besar akan merancang program-program kecemerlangan sekolah dan membantu para guru dalam menjalankan tanggungjawab sebagai pendidik. Analisis keseluruhan skor min pemboleh ubah kepimpinan pengajaran guru besar adalah seperti dalam jadual 1.

Jadual 2: Skor Min Pemboleh Ubah Kompetensi Profesionalisme Guru

\begin{tabular}{llll}
\hline Pemboleh Ubah & Min & Sisihan Piawai & Interprestasi \\
\hline $\begin{array}{l}\text { Kompetensi } \\
\text { Profesionalisme } \\
\text { Guru }\end{array}$ & 4.44 & .37 & Sangat Tinggi \\
\hline
\end{tabular}

Jadual 2 menunjukkan min keseluruhan bagi pemboleh ubah kompetensi profesionalisme guru ialah $4.44(\mathrm{SP}=.37)$. Nilai min ini menunjukkan bahawa pemboleh ubah kompetensi profesionalisme guru mempunyai nilai kompetensi profesionalisme pada tahap yang sangat tinggi. Ini menunjukkan guruguru sekolah rendah di zon Pedalaman, Sabah mempunyai tahap kompetensi profesionalisme yang tinggi dan mempunyai kefahaman terhadap strategi-strategi PdP. Walau bagaimanapun skor min ini masih boleh dipertingkatkan lagi agar kompetensi profesionalisme guru berada pada tahap yang maksimum. Dapatan kajian ini menunjukkan guru melaksanakan tugas dengan penuh ikhlas tanpa ada matlamat untuk kepentingan diri. Guru juga didapati menjalankan tugas dengan sempurna dan mempunyai komitmen yang tinggi. Guru-guru juga mematuhi peraturan-peraturan yang telah dikuatkuasakan. Dapatan kajian ini selaras dengan dapatan kajian Mohd. Nur Mustafa (2013), yang mendapati tahap penguasaan dalam aspek kompetensi profesional dalam kalangan guru-guru secara umumnya berada pada tahap memuaskan.

Jadual 3: Skor Min Pemboleh ubah Kompetensi Peribadi Guru

\begin{tabular}{llll}
\hline Pemboleh Ubah & Min & Sisihan Piawai & Interprestasi \\
\hline $\begin{array}{l}\text { Kompetensi Peribadi } \\
\text { Guru }\end{array}$ & 4.42 & .39 & Sangat Tinggi \\
\hline
\end{tabular}

Jadual 3 menunjukkan min keseluruhan bagi pemboleh ubah kompetensi peribadi guru ialah 4.42 $(\mathrm{SP}=.39)$. Nilai min ini menunjukkan bahawa pemboleh ubah kompetensi peribadi guru mempunyai nilai kompetensi peribadi pada tahap yang sangat tinggi. Ciri-ciri kompetensi peribadi guru-guru yang digemari oleh pelajar akan membolehkan guru mudah diterima dan mendapat sokongan daripada pelajar-pelajar seterusnya memudahkan proses penyampaian pengajaran guru. Pelajar menyanjung tinggi guru-guru yang memiliki ciri-ciri kompetensi peribadi yang berhemah tinggi. Ciri-ciri personal guru penting bagi membolehkan guru tersebut menjadi model yang berwibawa dan dihargai oleh para pelajar. Antara ciri kompetensi peribadi yang digemari oleh pelajar ialah mempunyai sifat amanah, ikhlas, berilmu pengetahuan, kasih sayang, sabar, adil, komunikasi yang baik dan dapat menyampaikan ilmu dengan menarik. Selain itu, penampilan juga memainkan peranan dalam membentuk peribadi seseorang guru. Guru perlu menampilkan ciri-ciri seperti pemilihan pakaian yang sesuai, kebersihan tubuh badan dan kekemasan diri.

Jadual 4: Skor Min Pemboleh Ubah Efikasi Pengajaran Guru

\begin{tabular}{llll}
\hline Pemboleh Ubah & Min & Sisihan Piawai & Interprestasi \\
\hline Efikasi Pengajaran Guru & 3.99 & .29 & Tinggi \\
\hline
\end{tabular}


Jadual 4 menunjukkan bahawa min keseluruhan bagi pemboleh ubah efikasi pengajaran guru ialah 3.99 $(\mathrm{SP}=.29)$. Nilai min ini menunjukkan bahawa pemboleh ubah efikasi pengajaran guru mempunyai nilai efikasi pengajaran pada tahap yang tinggi. Guru-guru yang percaya kepada kemampuan diri dalam melaksanakan tugasan pengajaran dan pembelajaran lazimnya akan menjadi idola pelajar. Marzano (2000), menyatakan tindakan guru dalam bilik darjah mempunyai impak dua kali ganda dalam pencapaian pelajar berbanding dengan polisi sekolah berkenaan kurikulum, penilaian kerjasama antara guru dan penglibatan masyarakat. Nilai positif yang ditunjukkan oleh guru-guru tersebut menjadi penanda aras kepada pencapaian kejayaan mereka pada masa hadapan. Pengukuran kualiti guru mempunyai perkaitan yang signifikan dengan pencapaian guru dalam memastikan kecemerlangan akademik pelajar. Guru berefikasi pengajaran tinggi sentiasa positif dalam menangani cabaran di dalam bilik darjah mahupun di luar, sentiasa kreatif dalam mengolah kesukaran dalam pembelajaran.

\section{Analisis Pengaruh Pemboleh ubah Kepimpinan Pengajaran Guru Besar, kompetensi profesionalisme guru dan kompetensi peribadi guru Terhadap Efikasi Pengajaran Guru-Guru Sekolah Rendah Di Zon Pedalaman, Sabah}

Analisis regresi berganda langkah demi langkah (stepwise multiple regression analysis) dilakukan bagi menentukan sumbangan pemboleh ubah kepimpinan pengajaran guru besar, kompetensi profesionalisme guru dan kompetensi peribadi guru terhadap efikasi pengajaran guru. Jadual 5 menunjukkan hasil analisis regrasi yang melibatkan pemboleh ubah peramal terhadap pemboleh ubah. Nilai $R$ adalah penentuan aras kekuatan keseluruhan pengaruh pemboleh ubah peramal terhadap pemboleh ubah kriteria manakala $R^{2}$ adalah nilai sumbangan varians terhadap pemboleh ubah kriteria.

Jadual 5 : Ringkasan Model Regresi

\begin{tabular}{lllll}
\hline Model (Pemboleh ubah) & $\boldsymbol{R}$ & $\boldsymbol{R}^{2}$ & $\boldsymbol{R}^{2}$ Terlaras & $\boldsymbol{S E}$ \\
\hline 1 (Kepimpinan pengajaran guru besar) & $.806^{\mathrm{a}}$ & .650 & .649 & .16910 \\
2 (kompetensi profesionalisme guru) & $.812^{\mathrm{b}}$ & .659 & .657 & .16710 \\
3 (kompetensi peribadi guru) & $.816^{\mathrm{c}}$ & .665 & .662 & .16584 \\
\hline
\end{tabular}

Dapatan analisis regrasi dalam jadual 5 menunjukkan model 1 nilai $R=.806$ yang menunjukkan dapatan regrasi pada aras kuat seperti mana yang dicadangkan oleh Sheridan dan Lyndall (2003). Nilai $R^{2}=.650$ merupakan nilai yang disumbangkan oleh kepimpinan pengajaran guru besar terhadap efikasi pengajaran guru pada nilai peratusan $65.0 \%$. Pemboleh ubah kepimpinan pengajaran guru besar dengan bilangan responden sebanyak 361 menunjukkan sumbangan varians sebanyak $65.0 \%$. Model 2 nilai $R=.812$ yang menunjukkan dapatan regrasi pada aras kuat. Nilai $R^{2}=.659$ merupakan nilai yang disumbangkan oleh kompetensi profesional guru terhadap efikasi pengajaran guru pada nilai peratusan $65.9 \%$. Pemboleh ubah kompetensi profesional guru dengan bilangan responden sebanyak 361 menunjukkan sumbangan varians sebanyak $65.9 \%$. Model 3 nilai $R=.816$ yang menunjukkan dapatan regrasi pada aras kuat. Nilai $R^{2}=.665$ merupakan nilai yang disumbangkan oleh kompetensi peribadi guru terhadap efikasi pengajaran guru pada nilai peratusan $66.5 \%$. Pemboleh ubah kompetensi peribadi guru dengan bilangan responden sebanyak 361 menunjukkan sumbangan varians sebanyak $66.5 \%$. Penetapan kekuatan pengaruh adalah mengikut nilai regresi yang dicadangkan oleh Sheridan dan Lyndall (2003).

Jadual 6: Analisis Varians (ANOVA)

\begin{tabular}{lllllll}
\hline Model & & Sum of Squares & $\boldsymbol{d f}$ & Mean Square & $\boldsymbol{F}$ & Sig. \\
\hline \multirow{3}{*}{1} & Regression & 19.057 & 1 & 19.057 & 666.468 & $.000^{\mathrm{b}}$ \\
\cline { 2 - 7 } & Residual & 10.265 & 359 & .029 & & \\
\cline { 2 - 7 } & Total & 29.322 & 360 & & 346.052 & $.000^{\mathrm{c}}$ \\
\hline \multirow{3}{*}{2} & Regression & 19.326 & 2 & 9.663 & & \\
\cline { 2 - 7 } & Residual & 9.996 & 358 & .028 & & \\
\cline { 2 - 7 } & Total & 29.322 & 360 & & & \\
\hline
\end{tabular}




\begin{tabular}{lllllll}
\hline \multirow{3}{*}{3} & Regression & 19.504 & 3 & 6.501 & 236.397 & $.000^{\mathrm{d}}$ \\
\cline { 2 - 6 } & Residual & 9.818 & 357 & .028 & & \\
\cline { 2 - 7 } & Total & 29.322 & 360 & & & \\
\hline
\end{tabular}

a. Pemboleh ubah Bersandar: Efikasi Pengajaran

b. Peramal: (Konstan), Kepimpinan Pengajaran Guru Besar

c. Peramal: (Konstan), Kompetensi Profesionalisme Guru

d. Peramal: (Konstan), Kompetensi Peribadi Guru

Jadual 6 menunjukkan pemboleh ubah kepimpinan pengajaran guru besar, kompetensi profesionalisme guru dan kompetensi peribadi guru berupaya memberi pengaruh terhadap tahap efikasi pengajaran guru. Aras kesignifikan Kepimpinan pengajaran guru besar menunjukkan $\mathrm{F}(1,359)=666.468, p=.000$ ) pada aras keertian $p<0.05$. Nilai $\mathrm{F}$ menunjukkan hubungan linear yang signifikan antara pemboleh ubah kepimpinan pengajaran guru besar dengan pemboleh ubah efikasi pengajaran guru. Pemboleh ubah kompetensi profesionalisme guru juga berupaya memberi pengaruh terhadap efikasi pengajaran guru pada aras kesignifikan $\mathrm{F}(2,358)=346.052, p=.000)$ pada aras keertian $p<0.05$. Nilai $\mathrm{F}$ menunjukkan hubungan linear yang signifikan antara pemboleh ubah kompetensi profesionalisme guru dengan pemboleh ubah efikasi pengajaran guru. Pemboleh ubah kompetensi peribadi guru juga berupaya memberi pengaruh terhadap efikasi pengajaran guru pada aras kesignifikan $\mathrm{F}(3,357)=$ $236.397, p=.000$ ) pada aras keertian $p<0.05$. Nilai $\mathrm{F}$ menunjukkan hubungan linear yang signifikan antara pemboleh ubah kompetensi peribadi guru dengan pemboleh ubah efikasi pengajaran guru. Oleh itu, hipotesis nul $\mathrm{H}_{0} 36$ yang menyatakan tidak terdapat pengaruh yang signifikan kepimpinan pengajaran guru besar, kompetensi profesionalisme guru dan kompetensi peribadi guru terhadap efikasi pengajaran guru dalam kalangan guru-guru sekolah rendah di zon Pedalaman, Sabah adalah ditolak.

Kekuatan pengaruh antara pemboleh ubah ditunjukkan dalam jadual 7. Keputusan analisis data menunjukkan bahawa bagi populasi kajian $(\mathrm{N}=361)$, tiga pemboleh ubah peramal merupakan peramal bagi skor tahap efikasi pengajaran guru. Jadual 7 menunjukkan $p$ kurang daripada nilai $a(0.05)$ kecuali nilai bagi kepimpinan pengajaran guru besar. Ini menunjukkan pengaruh signifikan antara pemboleh ubah bersandar dengan pemboleh ubah tidak bersandar. Dalam analisis ini, nilai $\mathrm{R}^{2}$ menunjukkan pengaruh keseluruhan pemboleh ubah tidak bersandar terhadap pemboleh ubah bersandar. Analisis ini mendapati ketiga-tiga pemboleh ubah memberi sumbangan kepada efikasi pengajaran guru. Pemboleh ubah kepimpinan pengajaran guru besar $(\beta=-.113, \mathrm{p}=.011)$ menyumbang sebanyak $65.0 \%$, pemboleh ubah kompetensi profesionalisme guru $(\beta=.368, \mathrm{p}=.000)$ menyumbang sebanyak $65.9 \%$ dan pemboleh ubah kompetensi peribadi guru $(\beta=.536, \mathrm{p}=.000)$ menyumbang sebanyak $66.5 \%$.

Jadual 7: Analisis Regresi Pemboleh ubah Kepimpinan Pengajaran Guru Besar, Kompetensi Profesionalisme Guru dan Kompetensi Peribadi Guru Terhadap Efikasi Pengajaran Guru $(\mathrm{N}=361)$

\begin{tabular}{|c|c|c|c|c|c|c|}
\hline Pemboleh ubah & B & $\beta$ & Nilai t & $P$ & $\mathbf{R}^{2}$ & Sumbangan \\
\hline $\begin{array}{lll}\text { Kepimpinan } & \text { Pengajaran } & \text { Guru } \\
\text { Besar } & & \end{array}$ & -.096 & -.113 & -2.546 & .011 & $\begin{array}{l}.65 \\
0\end{array}$ & $65.0 \%$ \\
\hline $\begin{array}{l}\text { Kompetensi Profesionalisme } \\
\text { Guru }\end{array}$ & .282 & .368 & 3.844 & .000 & $\begin{array}{l}.65 \\
9\end{array}$ & $65.9 \%$ \\
\hline Kompetensi Peribadi Guru & .392 & .536 & 6.014 & .000 & $\begin{array}{l}.66 \\
5\end{array}$ & $66.5 \%$ \\
\hline
\end{tabular}

*Signifikan pada aras $\mathrm{p}<0.05$

\section{Perbincangan}

Model Hallinger \& Murphy (1985) yang dijadikan landasan utama kajian menunjukkan pemboleh ubah kepimpinan pengajaran guru besar mempunyai pengaruh terhadap efikasi pengajaran guru. Dapatan kajian menunjukkan bahawa model kajian yang dicadangkan adalah sesuai dengan data yang diperoleh daripada responden dalam kajian ini. Model ini menunjukkan dapatan yang menggambarkan dengan jelas bahawa pemboleh ubah kepimpinan pengajaran guru besar merupakan peramal kepada tahap 
efikasi pengajaran guru bagi guru-guru di zon Pedalaman, Sabah. Penggalakan perkembangan profesionalisme adalah sangat penting bagi guru-guru di zon Pedalaman, Sabah dalam membantu tugas mereka dalam bilik darjah. Menurut Latip (2007), mutu pengajaran guru-guru dapat dipertingkatkan apabila aktiviti menyelia dan menilai pengajaran guru yang dianggap memotivasikan serta mengawal kualiti perkhidmatan guru yang profesional. Kajian ini menunjukkan pemboleh ubah peribadi guru juga merupakan peramal kepada tahap efikasi pengajaran guru di mana wujud pengaruh signifikan yang positif. Dapatan kajian ini adalah selari dengan dapatan kajian-kajian lepas seperti Rohani Arbaa et al., (2010), Klausen (2010) dan Maksic' \& Pavlovic' (2011), yang mendapati bahawa ciri kualiti guru merupakan peramal terbaik terhadap komitmen belajar dalam kalangan pelajar. Dapatan kajian boleh dijadikan panduan kepada para pengkaji lain pada masa hadapan, khasnya berkaitan dengan pengaruh kepimpinan pengajaran guru besar, kompetensi profesionalisme guru dan kompetensi peribadi guru terhadap efikasi pengajaran guru.

Berdasarkan perbincangan di atas, berikut dirumuskan beberapa cadangan untuk meningkatkan efikasi pengajaran guru bagi memastikan ianya memberi impak kepada penguasaan pelajar dan pencapaian akademik sekolah. Kajian selanjutnya disaran menggunakan guru-guru sekolah menengah dan juga para pensyarah di Institut Pengajian Tinggi sebagai responden. Kajian lanjut perlu dilakukan dengan mengambil kira skop lokasi, populasi dan latar belakang sekolah yang berbeza. Penyelidik juga mencadangkan supaya kajian selanjutnya dijalankan menggunakan rekabentuk eksperimental dan menggunakan pendekatan kualitatif.

\section{Kesimpulan}

Guru mempunyai peranan yang sangat penting dalam usaha membantu para pelajar dan juga organisasi sekolah untuk mencapai objektif yang sudah ditetapkan. Guru bukan sahaja penyampai ilmu akan tetapi guru juga memikul tanggung jawab besar agar dapat melahirkan modal insan yang cemerlang. Oleh itu, guru seharusnya mempunyai tahap efikasi pengajaran yang tinggi supaya berupaya menyempurnakan tugasannya dengan lebih efisien. Dalam konteks ini, selaras dengan dapatan kajian ini, kepimpinan pengajaran guru besar perlu diberi perhatian agar guru besar dapat memberikan contoh terbaik kepada guru-guru di bawah tadbirannya sehingga guru-guru dapat menunaikan tanggung jawab dengan lebih bermotivasi, bersemangat, seronok dengan profesion keguruan dan menganggap tugasan mendidik ini adalah satu ibadah. Guru-guru juga seharusnya mempunyai kompetensi profesionalisme dan peribadi yang tinggi supaya berupaya menjadi teladan kepada para pelajar. Pengamalan nilai-nilai profesionalisme dan peribadi dengan baik akan membantu guru-guru lebih berdedikasi terhadap tugas hakikinya sebagai pendidik.

Berdasarkan dapatan kajian, penyelidik mencadangkan beberapa cadangan untuk meningkatkan efikasi pengajaran guru seterusnya memberi impak kepada penguasaan pelajar dan pencapaian akademik sekolah. Penyelidik menyarankan kajian lanjutan menggunakan guru-guru sekolah menengah dan juga para pensyarah di Institut Pengajian Tinggi sebagai responden. Kajian lanjut perlu dilakukan dengan mengambil kira skop lokasi, populasi dan latar belakang sekolah yang berbeza. Penyelidik juga mencadangkan supaya kajian selanjutnya dijalankan menggunakan reka bentuk eksperimental dan menggunakan pendekatan kualitatif.

\section{Rujukan}

Ahmad Mahzan Ayub. (1995). Kaedah Penyelidikan Sosioekonomi. Kuala Lumpur: Dewan Bahasa dan Pustaka.

Amin Senin (2008). Pembangunan Profesional Guru. Kuala Lumpur: Utusan Publications.

Ashton, P. T. dan Webb, R.B. (1986). Making A Difference: The Teacher's Sence of Efficacy and Students Achievement. New York: Longman

Barak M. dan Shakhman L. (2007). Reform-based science teaching:Teacher's instructional practices and conceptions. Eurasia Journal of Mathematics, Science and Technology Education, $4(1): 11-20$ 
Barter, B. (2008). Rural Education: Learning To Be Rural Teachers. Journal of Workplace Learning, $20(7 / 8) 468-479$

Bryk, A., Sebring, P., Allensworth, E., Luppescu, S., \& Easton, J. (2010). Organizing School for Improvement: Lesson from Chicago. Chicago: The University of Chicago Press.

Fetherston, T. (2007). Becoming An Effective Teacher. Melbourne: Thomson

Gay, L. R. (2003). Education Research, Competencies For Analysis And Application. New Jersey: Merrill Prentice Hall.

Guskey, T. R. (2000). Evaluating Professional Development. California: Corwin Press, Inc.

Hallinger, P. dan Murphy, J.F. (1985). Assessing the instructional management behaviour of principles. The Elementary School Journal, 86(2):217-247

Hallinger, P. (2003). Leading Educational Change: Reflection on The Practice of Instructional and Transformational Leadership. Cambridge Journal of Education. 33(3): 329-351

Hallinger, P. (2011). Leadership For Learning: Lesson From 40 Years Of Empirical Research. Journal Of Educational Administration. 49(2):125-142

Henson, R. K. (2001). Perceived responsibility of prospective teachers for the moral development of their students. The Professional Educator, 23(2):47-53.

Jones, R. M. (2009). Science Teaching Time and Practice and Factors Influencing Elementary Teachers' Decisions About Both in Rural, Reservation Schools. Tesis Doktor Falsafah. Montana State University. UMI No:3350498

Klassen, R.M. et al,. (2009). Exploring the validity of a teachers self efficacy scale in five countries. Contemporary Educational Psychology, 34(1):67-76

Liaw E.C. (2009). Teacher efficacy of pre-service teachers in Taiwan: The influence of classroom teaching and group discussions. Teaching and Teacher Education, 25(1):176-180

M Nur Mustafa \& Norasmah Othman. (2009). Motivasi Kerja, Latihan Dalam Perkhidmatan dan Kompetensi Profesional Serta Hubungannya Terhadap Prestasi Kerja Guru Pekan Baru Provinsi

Riau, Indonesia. Prosiding Penyelidikan Siswazah. Universiti Kebangsaan Malaysia. Halaman 219-230.

Mannullang, M. (2002). Personnel Management. Jakarta: Ghalia Indonesian

Midthassel, U.V., Manger, T., Torsheim, T. (2002). Community Effects on Teacher Involvement in School Development Activity: A Study of Teachers in Cities, Smaller Towns and Rural Areas in Norway. Research Paper in Education 17(3) hlm. 293-303

Mohd. Yusri Ibrahim, \& Aziz Amin. (2014). Model Kepimpinan Pengajaran Pengetua dan Kompetensi Pengajaran Guru. Jurnal Kurikulum \& Pengajaran Asia Pasifik, Januari, 2(1), 11-25

Pusat Perkembangan Kurikulum. 2003. Kementerian Pelajaran Malaysia

Rahmad Sukor Ab. Samad \& Shahrir Jamaluddin. (2005). Peranan kepimpinan Guru Dalam Mempengaruhi Iklim Bilik Darjah. Masalah Pendidikan. Universiti Malaya. Halaman 117129.

Sashkin, M., \& Sashkin, M. G. (1993). Leadership And Culture Building In School. Dim Sinagatullin, I. M. 2001. Expectant Times: Rural Education in Russia. Journal Education Review, 53(1)37-45

Tillman, D. (2002). Living Values: Late Educational Programme Educators Training Guide. USA: HC Inc. 